\title{
Histopathological patterns and topographical distribution of Kaposi Sarcoma at Muhimbili National Hospital, Tanzania
}

\author{
Reginald Gervas, Edward Mgaya
}

School of Medicine, Muhimbili University of Health and Allied Sciences.

\begin{abstract}
Background: Kaposi sarcoma (KS) is derived from endothelial cell lineage; it is caused by Human Herpes Virus-8 (HHV-8) facilitated by immune suppression. KS remains one of the commonest sarcoma seen in Tanzania. The paucity of recent data makes monitoring the disease a challenge. This study describes the Histopathological Patterns and Topographical distribution of Kaposi Sarcoma at Muhimbili National Hospital, a tertiary care hospital in Tanzania.

Methods: A hospital-based retrospective cross-sectional study was done to review biopsies sent to the Central Pathology Laboratory (CPL), Muhimbili National Hospital from 2010 to 2014.

Results: A total of 818 cases representing $1.8 \%$ of all malignancies during the study period were enrolled in the study. The age of patients at diagnosis ranged from 6 months to 94 years old, with the median age being 37 years. Male to female ratio was 1.4:1.0. Females were younger than males $(\mathrm{p}<0.001)$. The majority of the lesions were in the lower limbs, $352(64.1$ $\%$ ). Nodular KS accounted for $74.5 \%$ of all cases.

Conclusion: Kaposi's sarcoma remains a common malignancy. The patients present late at diagnosis. Early diagnosis and improved treatment protocols remain to be key steps towards reducing the burden of KS.

Keywords: Kaposi's Sarcoma, Histopathological Patterns, Topographical distribution.

DOI: https:// dx.doi.org/10.4314/abs.v21i4.29

Cite as: Gervas R, Mgaya E. Histopathological patterns and topographical distribution of Kaposi Sarcoma at Mubimbili National Hospital, Tanzania. Afri Health Sci. 2021;21(4):1733-8. bttps:/ / dx.doi.org/10.4314/abs.v21i4.29
\end{abstract}

\section{Introduction}

Kaposi sarcoma (KS) was first described by Moritz Kaposi, a Hungarian dermatologist in 1872; he described it as "idiopathic multiple pigmented sarcoma of the skin" ". The etiological agent associated with KS was discovered in 1994 by Chang and his colleagues; it is called the Human Herpes Virus 8 (HHV-8), also known as KS-associated Human Herpes Virus ${ }^{2}$. HHV-8 can be transmitted through saliva, organ transplantation and blood transfusion ${ }^{3}$. The clinical relevance of KS includes both cosmetic disfigurement and considerable morbidity and mortality.

The epidemiological classification of Kaposi's sarcoma has four displays: the classic KS, the endemic or African $\mathrm{KS}$, the iatrogenic KS and the epidemic (AIDS-associated) KS. Classic KS is a slow progressing neoplasm which affected mainly elderly men of Mediterranean

\section{Corresponding author: \\ Reginald Gervas, P.O.Box 6396 Mbeya, Tanzania \\ Mobile: +255752032646 \\ Email: gervasreginald@gmail.com}

and Eastern European region, especially Ashkenazi Jews ${ }^{4}$. Endemic KS, also known as African KS was described in the 1950s. This form of KS has a more aggressive evolution than the classic form and the skin is extensively infiltrated; it affects both children and adults ${ }^{5,6}$. Iatrogenic KS, also known as Immunosuppression-associated KS develops in individuals such as those receiving organ transplant ${ }^{7}$. The endemic KS, also known as AIDS-associated KS is a major AIDS-defining malignancy; usually, it develops among HIV patients who do not receive highly active antiretroviral therapy $\left(\right.$ HAART $^{8}$.

Endemic (AIDS-associated) KS experienced an explosive growth in sub-Saharan Africa with the emergence of human immunodeficiency virus (HIV) infection in the region in early the 1990 s $^{9}$. For example in Uganda KS became the leading cancer in males (about half of all registered cases) and the second most frequent (17.9\%) in females in the early 1990s, this was the time when the AIDS epidemic was in its evolution in the region ${ }^{10}$. The discovery and widespread use of highly active antiretroviral therapy (HAART) led to a tremendous decrease in the incidence of AIDS-related sarcoma (AIDS-KS) especally in developed countries ${ }^{11,12}$. The developing 
countries have been experiencing a modest decrease in the HAART era as compared to the developed countries ${ }^{13,14}$. This may be attributed to late initiation of HAART (starting HAART when CD4+<200) before the test and start era, poor coverage of HAART, less use of more potent HAART such protease inhibitors in those failing treatment and other preventive or curative therapies for AIDS-associated cancers ${ }^{15-17}$.

For unknown reasons, $\mathrm{KS}$ is more common in males than in females ${ }^{13,18}$. This male versus female incidence difference is more prevalent in HIV-negative adults ${ }^{13}$. The clinical description of KS is the presence of hyper-pigmented lesions that grow in mucosa such as skin, mucous membranes lining the mouth, nose, throat or viscerally in lymph nodes, or other internal organs 19, 20. The lower limbs are predominantly the most reported affected site by KS ${ }^{13,20,21}$.

The histology of KS lesions from the skin, lymph nodes and viscera is very similar. The histological hallmark of KS is the presence of spindle-shaped cells of endothelial origin with slit-like blood vessels and peripheral inflammatory cells 4 . KS develops from patch (earliest focus of KS lesions), plaque (more indurated, oedematous and violaceous), or nodular (visible mass dominated by spindle cells) stages (Figure 1, Figure 2 \& Figure 3) ${ }^{22-24}$; the same patient can have lesions at different types of stages 6 .

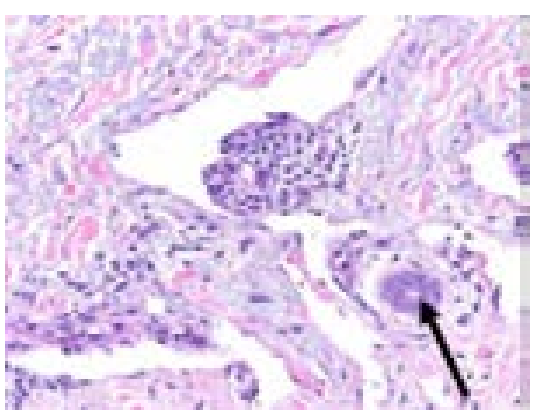

Figure 1: Patch stage Kaposi sarcoma showing newly formed vessels protruding into a larger vascular space characteristic of the promontory sign (H\&E, 200X).

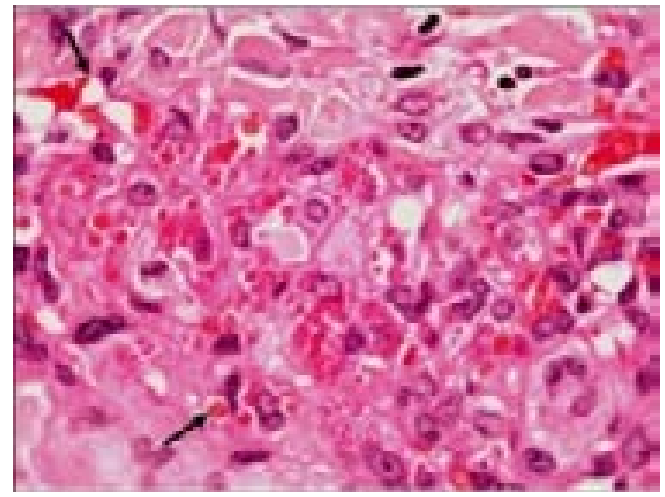

Figure 2: Plaque stage Kaposi sarcoma. numbers of intracellular and extracellular eosinophilic hyaline globules are visible in this field (H\&E, 400X)

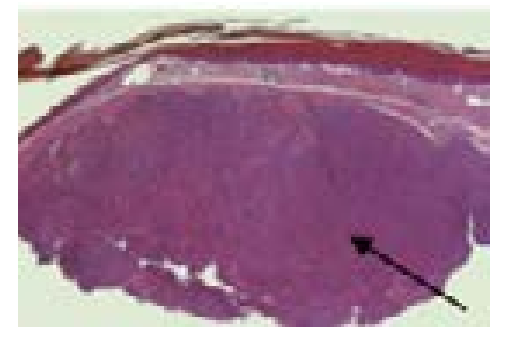

Figure 3: Nodular Kaposi sarcoma. The dermis is expanded by a solid tumour nodule (H\&E, 20X). 
KS remains to be the leading malignant vascular tumour and second most prevalent cancer seen in Tanzania $^{15,20,25}$. This necessitates closer monitoring on the $\mathrm{KS}$ in the country given that most patients seek medical care at late stages of the disease. However, despite this observation, there is a paucity of information regarding this condition in Tanzania. The aim of this study was therefore to describe the five-year experience in histological staging and topographical distribution of KS among patients receiving treatment at Muhimbili $\mathrm{Na}-$ tional Hospital, a national tertiary hospital in Tanzania.

\section{Materials and Methods \\ Study site and data collection}

This was a retrospective study whereby histologically confirmed cases of Kaposi's sarcoma from 1st January 2010 to 31 st December 2014 were retrieved from the archives at Central Pathology Laboratory at Muhimbili National Hospital (MNH). MNH receives referred patients from all over the country, and it also serves as a national consultant hospital, a zonal referral hospital for East and Southern Tanzania as well as a university teaching hospital for Muhimbili University of Health and Allied Sciences (MUHAS). It has a 1,500-bed capacity, attending approximately 1,200 inpatients per week and approximately 1,200 outpatients per day.

Inclusion criteria were patients of both genders with histologically confirmed Kaposi's sarcoma.

Data concerning age, gender, histological type and top- ographic site of Kaposi's sarcoma were recorded. Patients' identifiers such as names were not recorded.

\section{Statistical data analysis}

The statistical analysis was performed using the Statistical Package for Social Sciences (SPSS) version 20.0 for Windows (SPSS, Chicago, Illinois, USA). The student $t$ test was used to test for significance of associations between the predictor and outcome variables in the continuous variables. The level of significance was considered as $\mathrm{P}<0.05$.

\section{Ethical approval}

Ethical clearance was sought from the MUHAS Institutional Review Board and permission to conduct the study at the national hospital was granted by administration.

\section{Results}

During the study period, a total of 45,250 malignancies were registered at Central Pathology Laboratory at MNH. Of these, $818(1.8 \%)$ were histologically confirmed Kaposi's sarcoma giving an average of 164 cases annually. The age of patients at diagnosis ranged from 6 months to 94 years with a median of 37 years (IQR = $31-45$ years). The modal age group was $31-40$ years. Of all cases, $473(57.8 \%)$ were males and $345(42.2 \%)$ females; this gave male to female ratio of 1.4:1.0. Females were younger than males (mean age of 36.5 years vs. males 41.7 years; $\mathrm{p}<0.001)$, Table 1 .

Table 1: Age distribution

\begin{tabular}{|l|l|l|l|}
\hline Age (years) & $\begin{array}{l}\text { Male } \\
\mathbf{n}(\%)\end{array}$ & $\begin{array}{l}\text { Female } \\
\mathbf{n}(\%)\end{array}$ & $\begin{array}{l}\text { Total } \\
\mathbf{N}(\%)\end{array}$ \\
\hline$<15$ & $13(2.8)$ & $8(2.3)$ & $21(2.6)$ \\
\hline $15-20$ & $9(1.9)$ & $5(1.5)$ & $14(1.7)$ \\
\hline $21-30$ & $60(12.7)$ & $92(26.9)$ & $152(18.7)$ \\
\hline $31-40$ & $171(36.3)$ & $145(42.4)$ & $316(38.9)$ \\
\hline $41-50$ & $101(21.4)$ & $56(16.4)$ & $157(19.3)$ \\
\hline $51-60$ & $69(14.6)$ & $21(6.1)$ & $90(11.1)$ \\
\hline $61-70$ & $31(6.6)$ & $6(1.8)$ & $37(4.6)$ \\
\hline $71-80$ & $10(2.1)$ & $7(2.0)$ & $17(2.1)$ \\
\hline$>80$ & $7(1.5)$ & $2(0.6)$ & $9(1.1)$ \\
\hline Total & $\mathbf{4 7 3 ( 5 7 . 8 )}$ & $\mathbf{3 4 5 ( 4 2 . 2 )}$ & $\mathbf{8 1 8}$ \\
\hline
\end{tabular}

Table 2 shows the pathological stages and phases of KS. The lower limbs were the most common site for KS occurrence. In all cases, 352 (64.1\%) were present in the lower limbs. This was followed by the occurrence of KS in the oral cavity, 62 cases $(11.3 \%)$. There were two (2) cases $(0.4 \%)$ of $\mathrm{KS}$ in ovaries.
The most common pathological stage of KS observed in this study was the Nodular stage, this accounted for 461 cases $(74.5 \%)$ of all the KS lesions seen. Patchy and plaque stages accounted for the remaining 120 cases $(19.4 \%)$ and 38 cases $(6.1 \%)$ respectively. 
Table 2: Anatomical site of distribution of KS

\begin{tabular}{|l|l|}
\hline Anatomical site & $\mathbf{n}(\%)$ \\
\hline Lower limb & $352(64.1)$ \\
\hline Oral cavity & $62(11.3)$ \\
\hline Upper limb & $39(7.1)$ \\
\hline Iymph nodes & $24(4.4)$ \\
\hline Oropharynx & $34(6.2)$ \\
\hline Head and neck & $19(3.5)$ \\
\hline Trunk & $7(1.3)$ \\
\hline Breast & $4(0.7)$ \\
\hline Penis & $4(0.7)$ \\
\hline Ovary & $2(0.4)$ \\
\hline Bronchus & $1(0.2)$ \\
\hline Anus & $1(0.2)$ \\
\hline * There were 167 biopsies from an unspecified part of the skin. \\
There were 102 biopsies without a documented site of collection.
\end{tabular}

\section{Discussion}

In this study, Kaposi's sarcoma accounted for $1.8 \%$ of all malignancies recorded at the Central Pathology Laboratory in Muhimbili National Hospital in the 5-year study period from 2010 to 2014. This figure is lower than the figure of $2.4 \%$ reported Chayla et al in the Lake Zone of the country around the same time as this study ${ }^{20}$. Another study at Ocean Road Cancer Institute (ORCI) deduced a decline in annual percentage of KS cases $10.1 \%$ in 2003 to $7.4 \%$ in 2011 ; this was attributed to increased use of HAART during this period ${ }^{25}$. The reason for these high figures at ORCI might be because it is the only cancer centre in Tanzania; it offers both radiotherapy and chemotherapy.

Kaposi's sarcoma was more prevalent in males than in females, with a male to female ratio of 1.4:1.0. Male predominance has been observed in many other studies $^{21,25-27}$. A study done at the same hospital 35 years ago revealed the male to female ratio to be 4.1:128. In South Africa, it is estimated that the incidence of KS has doubled in men while increasing by seven folds in women in the past 20 years 29 . The difference in the rate of KS between the sexes reflects the emergence of AIDS-related KS which has reduced male to female ratio gap. A national survey that was conducted in Tanzania in 2016 revealed HIV prevalence in females to be as twice as much as compared to males, $6.2 \%{ }^{30}$.

Kaposi's sarcoma has shown to affect all age groups and in this study, a 6 months old was diagnosed to have
$\mathrm{KS}$, the youngest ever patient diagnosed to have KS was 6 days old ${ }^{31,32}$. On average, males were older than females. This is in agreement with other previous studies in sub-Saharan Africa ${ }^{13,21,25,29}$. Majority of the subjects fell between the ages of 31 and 40 years. This is the same age range that was most affected in the previous studies in sub-Saharan Africa ${ }^{20,33,34}$.

In this study, the commonest sites of the disease were the skin, $77.6 \%$. Skin presentation is the commonest mode of presentation, other sites especially the oral cavity and gastrointestinal tract are also common ${ }^{25,35,36}$. This also might be attributed by lack of facilities and pro-activeness in the diagnosis of visceral KS in our settings as most of the patients might be mislabeled to have Pulmonary Tuberculosis or other chronic illness ${ }^{27}$. Overall, more than half of the patients presented with lesions in the lower half of the body $(64 \%)$. Lower limb KS predominance has been observed in many similar studies $7,9,13,20,25,37$. The reason for the lower limb to be the commonest site for Kaposi's sarcoma is not clearly understood.

Nodular KS accounted for $461(74.5 \%)$ of all KS biopsies in this study. Similar findings were seen in other studies in East Africa and the globe 33, 38, 39. Many studies have attributed this high prevalence of Nodular KS pattern to late presentation of the patients to healthcare facilities; many patients present in late stages for cancer diagnosis ${ }^{20,21,25,37}$. 


\section{Conclusion}

This study has shown Kaposi's sarcoma remains a common malignant tumour in the country. Majority of the patients presented with the disease in the fourth decade of their lives. The patients present late with the disease, they present with Nodular KS. Early diagnosis and improved treatment protocols remain to be key steps towards reducing the burden caused by this disease.

\section{Conflict of interest disclosures}

The authors declare that they have no competing interests. The study was approved by the ethical committee of the Muhimbili University of Health and Allied Sciences (MUHAS), Tanzania. Reginald Gervas participated in study design, literature search, data collection and analysis, manuscript writing, editing and submission of the manuscript. Edward Mgaya participated in data analysis, manuscript writing and editing. Also, Edward Mgaya supervised the study. All authors read and approved the final manuscript.

\section{References}

1. Sternbach G, \& Varon J. Moritz Kaposi: Idiopathic pigmented sarcoma of the skin. The Journal of Emergency Medicine. 1995; 13(5):671-674. doi:10.1016/07364679(95)00077-N

2. Chang Y, Cesarman E, Pessin M, et al. Identification of herpesvirus-like DNA sequences in AIDS-associated Kaposi's sarcoma. Science. 1994; 266(5192):18651869. doi: $10.1126 /$ science. 7997879

3. Minhas V \& Wood C. Epidemiology and Transmission of Kaposi's Sarcoma-Associated Herpesvirus. Viruses. 2014; 6(11):4178-4194. doi: 10.3390/v6114178

4. Gessain A \& Duprez R. Spindle cells and their role in Kaposi's sarcoma. International Journal of Biochemistry and Cell Biology. 2005; 37(12):2457-2465. doi:10.1016/j. biocel.2005.01.018

5. James W, Elston D \& Berger T. Andrew's Diseases of the Skin: Clinical Dermatology. London: Saunders Elsevier; 2011.

6. Mesri EA, Cesarman E \& Boshoff C. Kaposi's sarcoma and its associated herpesvirus. Nat Rev Cancer. 2010; 10(10):707-719. doi: 10.1038/nrc2888

7. Hosseini-Moghaddam M, Soleimanirahbar A, Mazzulli T, Rotstein C \& Husain S. Post renal transplantation Kaposi's sarcoma: a review of its epidemiology, pathogenesis, diagnosis, clinical aspects, and therapy. Transplant Infectious Disease. 2012; 14(4):338-345. doi: 10.1111/j.1399-3062.2011.00714.x

8. Martin J, Wenger M, Busakhala N, et al. Prospective evaluation of the impact of potent antiretroviral thera- py on the incidence of Kaposi's Sarcoma in East Africa: findings from the International Epidemiologic Databases to Evaluate AIDS (IeDEA) Consortium. Infectious Agents and Cancer. 2012; 7(1):019. doi:10.1186/17509378-7-S1-O19.

9. Mbulaiteye M, Katabira T, Wabinga H, et al. Spectrum of cancers among HIV-infected persons in Africa: The Uganda AIDS-Cancer Registry Match Study. International Journal of Cancer. 2006; 118(4):985-990. doi: 10.1002/ijc.21443

10. Wabinga R, Mugerwa W, Parkin M \& Wabwire-Mangen F. Cancer in Kampala, Uganda, in 1989-91: Changes in incidence in the era of AIDS. International Journal of Cancer. 1993; 54(1):26-36. doi:10.1002/ijc.2910540106.

11. Pipkin S, Scheer S, Okeigwe I, Schwarcz S, Harris H \& Hessol A. The effect of HAART and calendar period on Kaposi's sarcoma and non-Hodgkin lymphoma: Results of a match between an AIDS and cancer registry. AIDS. 2011; 25(4):463-471. doi: 10.1097/QAD. 0b013e32834344e6

12. Bower M, Weir J, Francis N, et al. The effect of HAART in 254 consecutive patients with AIDS-related Kaposi's sarcoma. AIDS. 2009; 23(13):1701-1706. doi:10.1097/QAD.0b013e32832d080d

13. Wabinga R, Parkin M, Wabwire-Mangen F \& Nambooze S. Trends in cancer incidence in Kyadondo County, Uganda, 1960-1997. British Journal of Cancer. 2000; 82(9):1585-1592. doi:10.1054/bjoc.1999.1071

14. Mutyaba I, Phipps W, Krantz E, et al. A Population-Level Evaluation of the Effect of Antiretroviral Therapy on Cancer Incidence in Kyadondo County, Uganda, 1999 - 2008. J Acquir Immune Defic Syndr. 2015; 69(4):481-486. doi: 10.1097/QAI.0000000000000620

15. Semango P, Charles M, Swai I, et al. Prevalence and associated risk factors for Kaposi's sarcoma among HIV-positive patients in a referral hospital in Northern Tanzania: a retrospective hospital-based study. BMC Cancer. 2018; 18(1):1258. doi: 10.1186/s12885-018$5155-2$.

16. Kasamba I, Baisley K, Mayanja N, Maher D \& Grosskurth H. The impact of antiretroviral treatment on mortality trends of HIV-positive adults in rural Uganda: a longitudinal population-based study, 19992009. Tropical Medicine \& International Health. 2012; 17(8):e66-e73. doi: 10.1111/j.1365-3156.2012.02841.x 17. Lahuerta M, Ue F, Hoffman S, et al. The Problem of Late ART Initiation in Sub-Saharan Africa: A Transient Aspect of Scale-up or a Long-term Phenomenon? Journal of Health Care for the Poor and Underserved. 2013; 24(1):359-383. doi: 10.1353/hpu.2013.0014.

18. Parkin M, Sitas F, Chirenje M, Stein L, Abratt R \& 
Wabinga H. Part I: Cancer in Indigenous Africans-burden, distribution, and trends. The Lancet Oncology. 2008; 9(7):683-692. doi: 10.1016/S1470-2045(08)70175-X

19. Pantanowitz L \& Dezube J. Kaposi sarcoma in unusual locations. BMC Cancer. 2008; 8:190. doi:10.1186/1471-2407-8-190

20. Chalya P, Mbunda F, Rambau P, et al. Kaposi's sarcoma: a 10-year experience with 248 patients at a single tertiary care hospital in Tanzania. BMC Research Notes. 2015; 8(1):440. doi: 10.1186/s13104-015-1348-9

21. Ahmed A, Muktar H \& Bujage M. Epidemiological and clinical features of AIDS-associated Kaposi's sarcoma in Northern Nigeria. Arch Int Surg. 2013; 16(3):39-34. doi: 10.4103/2278-9596.117132

22. Dittmer D. Restricted Kaposi's sarcoma (KS) herpesvirus transcription in KS lesions from patients on successful antiretroviral therapy. mBio. 2011; 2(6). doi:10.1128/mBio.00138-11

23. Dupuy S, Lambert M, Zucman D, et al. Human herpesvirus 8 (HHV8) sequentially shapes the NK cell repertoire during the course of asymptomatic infection and Kaposi sarcoma. PLoS Pathogens. 2012; 8(1). doi:10.1371/journal.ppat.1002486

24. Ackerman A. Histologic features of Kaposi's sarcoma and simulators of it. In: Cerimele D, ed. Kaposi's Sarcoma. New York: Spectrum Publications, Inc.; 1985: p71-79.

25. Koski L, Ngoma T, Mwaiselage J, Le L \& Soliman S. Changes in the pattern of Kaposi's sarcoma at Ocean Road Cancer Institute in Tanzania (2006-2011). International Journal of STD \& AIDS. 2015; 26(7):470-478. doi: $10.1177 / 0956462414544724$

26. Mandong B, Chirdran L, Anyebe A \& Mannaseh A. Histopathological features of Kaposi's sarcoma in Jos: a 16 year review. Annals of African Medicine. 2004; 3(4):174-176. Available at: https://www.researchgate. net/publication/27788910_Histopathological_Study_ of_Kaposi's_Sarcoma_in_Jos_A_16-year_Review. Accessed April 11, 2020

27. Halfan C \& Khamza M. Survival and its determinants of Kaposi sarcoma in Tanzania: Retrospective study. Journal of Clinical Oncology. 2014; 32(15). doi: 10.1200/jco.2014.32.15_suppl.e20607

28. Amir H, Kaaya E \& Biberfeld P. Kaposi’s Sarcoma in African Women Before and During HIV-AIDS Epidemic. Austral-Asian Journal of Cancer. 2000; 1(1):42-48. 29. Mosam A, Hurkchand H, Cassol E, et al. Characteristics of HIV-1-associated Kaposi's sarcoma among women and men in South Africa. International Journal of STD \& AIDS. 2008; 19(6):400-405. doi :10.1258/ ijsa.2008.007301
30. TACAIDS. Tanzania HIV Impact Survey( THIS) 2016-2017 Final Report. Tanzania; 2018:48. https:/ / phia.icap.columbia.edu/wp-content/uploads/2019/06/FINAL_THIS-2016-2017_Final-Report_06.21.19_for-web_TS.pdf. Accessed April 11, 2020.

31. Wamburu G, Masenga E, Moshi E, Schmid-Grendelmeier P, Kempf W \& Orfanos C. HIV - associated and non - HIV associated types of Kaposi's sarcoma in an African population in Tanzania. Status of immune suppression and HHV-8 seroprevalence. European Journal of Dermatology. 2006; 16(6):677-682. doi:10.1684/ ejd.2006.0015

32. Gutierrez-Ortega P, Hierro-Orocoz S \& Sanchez-Cisnero R. Kaposi's sarcoma in a 6 day old infant with HIV. Archives of Dermatology. 1989; 125:432433. doi: 10.1001/archderm.1989.01670150122023

33. Kaaya E. Kaposi's sarcoma in Tanzania and Switzerland: a retrospective comparative study. European Journal of Cancer. 1992; 28A(11):1890-4. doi: 10.1016/09598049(92)90030-6.

34. Pitche P, Kombate K, Owono F \& Tchangai-Walla K. Kaposi's sarcoma in a hospital setting in Lomé (Togo): a study of 93 cases. International Journal of Dermatology. 2007; 46(s1):42-44. doi: 10.1111/j.13654632.2007.03464.x.

35. Dezube B. Clinical presentation and natural history of AIDS--related Kaposi's sarcoma. Hematology/oncology clinics of North America. 1996; 10(5):1023-1029. doi: 10.1016/S0889-8588(05)70382-8

36. Enow O, Verla V, Ashuntantang G \& Ndom P. Kaposi Sarcoma: A review of 387 cases in Younde, Cameroon. Global Advanced Research Journal of Medicine and Medical Sciences. 2013; 2(9):193-198. Available at: https://garj.org/garjmms/9/2013/2/9/kaposi-sarcoma--a-review-of-387-cases-seen-in-yaounde-cameroon. Accessed April 09, 2020.

37. Forae G \& Obaseki D. Trends and Histopathological Patterns of Kaposi Sarcoma at The University of Benin Teaching Hospital, Benin City, Nigeria. Oman Medical Journal. 2018; 33(4):337-341. doi: 10.5001/omj.2018.61

38. Urassa W, Kaaya E, Kitinya JN, et al. Immunological profile of endemic and epidemic Kaposi's sarcoma patients in Dar-es-Salaam, Tanzania. International Journal of Molecular Medicine. 1998; 1(6):979-982. doi: 10.3892/ ijmm.1.6.979.

39. Mwakigonja A, Pyakurel P, Kokhaei P, et al. Human herpesvirus-8 (HHV-8) sero-detection and HIV association in Kaposi's sarcoma (KS), non-KS tumors and non-neoplastic conditions. Infectious Agents and Cancer. 2008; 3:10. doi:10.1186/1750-9378-3-10 